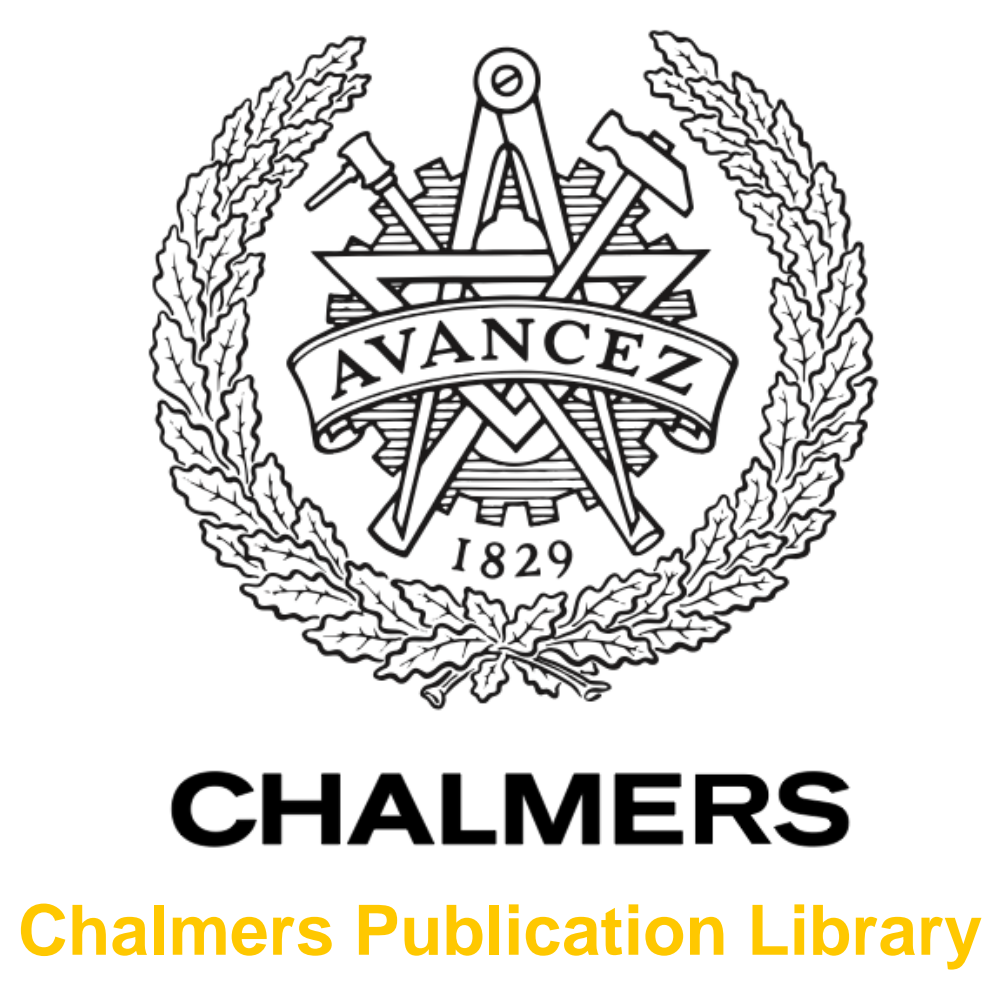

\title{
The impact of supply chain relationships and automatic data communication and registration on forecast information quality
}

This document has been downloaded from Chalmers Publication Library $(\mathrm{CPL})$. It is the author's version of a work that was accepted for publication in:

International Journal of Physical Distribution and Logistics Management

Citation for the published paper:

Jonsson, P. ; Gustavsson, M. (2008) "The impact of supply chain relationships and automatic data communication and registration on forecast information quality". International Journal of Physical Distribution and Logistics Management, vol. 38(4), pp. 280-295.

http://dx.doi.org/10.1108/09600030810875382

Downloaded from: http://publications.lib.chalmers.se/publication/70821

Notice: Changes introduced as a result of publishing processes such as copy-editing and formatting may not be reflected in this document. For a definitive version of this work, please refer to the published source. Please note that access to the published version might require a subscription. 
Full reference: Jonsson, P. and Gustavsson, M. 2008. The impact of supply chain relationships and automatic data communication and registration on forecast information quality. International Journal of Physical Distribution and Logistics Management. 38(4): 280-295.

\title{
THE IMPACT OF SUPPLY CHAIN RELATIONSHIPS AND AUTOMATIC DATA COMMUNICATION AND REGISTRATION ON FORECAST INFORMATION QUALITY
}

\author{
Patrik Jonsson \& Mattias Gustavsson \\ Chalmers University of Technology \\ Gothenburg, Sweden \\ E-mail: patrik.jonsson@chalmers.se
}

\begin{abstract}
Purpose - The purpose of this paper is to explain the effects of the customer-supplier relationship and of automatic forecast data communication and registration on the perceived information quality of forecasts.

Design/methodology/approach - A conceptual model and three hypotheses are derived. The empirical analysis is based on survey data from 219 Swedish manufacturing companies.

Findings - Findings show that the customer-supplier relationship and automatic data communication and registration have significant impact on the perceived quality of forecast information received from a downstream customer in the supply chain. The reliability and timeliness of the forecast information are affected to about the same extent by both the relationship type and the data communication and registration strategy. Credibility is correlated with the relationship type, while the completeness, validity and conciseness of the received forecast are operative issues depending mainly on the communication strategy.

Research limitations/implications - Using single informants, focal customers and some single-item constructs in research design.

Practical implications - The paper explains how various dimensions of forecast information quality are affected by different factors, thus guiding how to differentiate information quality improvement work in diverse situations.

Originality/value - Detailed empirical studies of supply chain information exchange, especially focusing on explaining causes of high-quality information exchange, are lacking in the literature and demanded in industry.

Keywords - ICT, forecast information, supply chain management, business relationships, information quality.
\end{abstract}

\section{INTRODUCTION}

Several scholars have emphasized the importance of sharing forecast data between customers and suppliers in order to decrease suppliers’ planning uncertainty (e.g. Cachon and Fisher, 2000; Kelle and Akbulut, 2005). But forecasts that are communicated upstream in a supply chain often have quality defects, such as being delayed, difficult to understand, incorrect, etc. (e.g. Petersen et al., 2005; Gustavsson and Jonsson, 2007). Such quality deficiencies decrease the usefulness of information and may have negative performance impact (e.g. McCarthy and Golicic, 2002; van der Vorst and Beulens, 2002).

To improve the information quality when exchanging forecasts, it is necessary to understand the causes of the deficiencies. Causes can be related to the customer-supplier relationship (Forslund and Jonsson, 2007), i.e. the level of trust and the type of communication and cooperation, between the 
Full reference: Jonsson, P. and Gustavsson, M. 2008. The impact of supply chain relationships and automatic data communication and registration on forecast information quality. International Journal of Physical Distribution and Logistics Management. 38(4): 280-295.

information sender (customer company) and information receiver (supplying company). If the information sender understands how the receiver is using the information, and if they have a trustworthy and continuous dialogue, there is a greater possibility for the sender to provide information that is perceived by the receiver to have high quality when used in its planning processes. Causes of high information quality can also be related to the data communication and registration, i.e. communication technology used and level of standardization and automatic interface in the process of generating, transferring and registering the information. For example, standardized electronic data interchange (EDI) communication significantly reduces time delays in the transferred information (Feng and Yuan, 2006).

There are consequently logical causes of different information quality levels, but there is a lack of knowledge about the levels of significant information quality impact from various causes. No identified study has explained the impact of the customer supplier relationship or of automatic communication and registration of forecast data, or the interaction effect between the relationship and automatic data communication and registration on information quality dimensions. This should be important to know for companies in order to focus the improvement effort on the right activities. The present article attempts to fill some of these gaps and thereby extend the knowledge about how to exchange highquality information in supply chains. The purpose is to explain the effects of the customer-supplier relationship and of automatic communication and registration of forecast data on the perceived forecast information quality. The focus is on forecast information generated by an external customer and communicated to and used in a supplying company. The study takes the perspective of the supplying company, i.e. the receiver and user of the data, and analyzes the supplier's perception of the information quality.

The theoretical basis and hypotheses, and a conceptual model for the study, are presented in the next section of the paper. This is followed by a methodology section describing the design and collection of empirical survey data in Swedish manufacturing companies. The last sections of the article present the empirical findings, hypotheses testing, discussion and conclusions.

\section{THEORY}

Information quality

Different dimensions of information quality have been defined in the literature (e.g. Lee et al., 2002; Petersen, 2005; Gustavsson and Wänström, 2008; Forslund and Jonsson, 2007). Six of these dimensions of forecast information quality are here considered of particular importance in relation to the customer-supplier relationship and automatic data communication and registration. Forecast information being complete means that it contains all necessary information for being used. Conciseness deals with the ease of accessing the data without further processing, e.g. adapting an item code or entering it manually into the supplier's planning system. Reliability refers to the probability that a forecast will remain unchanged. Unreliable information means uncertainty to the supplying company. Forecast information being timely means that it is provided within the agreed time, when the information customer wants it. It is also concurrent with the situation, i.e. the state of information used for decision-making corresponds to the situation, so the data represented are not time-phased with regard to when they were registered and presented. Validity concerns the degree to which the information sender and receiver use the same definitions and measures of the information exchanged. Credibility measures the perceived trust in the forecast from the user's perspective. Credible forecasts are important to avoid speculation. Credibility is in the long run influenced by the other dimensions.

The criticality of the forecast information quality can be expected to differ between dimensions. The reliability dimension has been shown to be especially critical for forecast information (Forslund and 
Full reference: Jonsson, P. and Gustavsson, M. 2008. The impact of supply chain relationships and automatic data communication and registration on forecast information quality. International Journal of Physical Distribution and Logistics Management. 38(4): 280-295.

Jonsson, 2007) but previous studies have also identified conciseness, timeliness and credibility as important dimensions (Gustavsson and Jonsson, 2007).

\section{Collaborative relationship}

A successful customer-supplier relationship is often defined as a collaborative relationship, characterized by a high level of trust, commitment, shared values, communication, adaptation, positive bases of power, cooperation, relationship bonds and dependence (e.g. Zineldin, 1998; Narasimhan and Nair, 2005; Petersen et al., 2005).

Trust is often emphasized as the most important issue for managing long-term relationships and cooperation, but it is also a result of long-term relationships between parties (e.g. Spekman et al., 1998; Min and Mentzer, 2000). Moorman et al. (1993) define trust as "a willingness to rely on an exchange partner in whom one has confidence" and Anderson and Narus (1990) focus on the perceived outcomes of trust when defining it as "the firm's belief that another company will perform actions that will result in positive outcomes for the firm as well as not take unexpected actions that will result in negative outcomes". Trust consequently exists when one party has confidence in a collaborative exchange partner's reliability and integrity (Zineldin and Jonsson, 2000).

Cooperation is possible also without trust (e.g. Mayer et al., 1995) but communication is always necessary. Spekman et al. (1998) highlight communication processes, characterized by high frequency and high level of contact between the partners, as one of the most important supply chain management themes. An important part of communication is information-sharing. Especially a lack of forecast information-sharing is often emphasized as a common cause of uncertainty in supply chain planning (e.g. Kwon and Suh, 2005). Both the content of, and participation in, the information exchange are considered significant for determining the degree to which the parties understand each other's goals and are able to coordinate their efforts to achieve those goals (Mohr and Spekman, 1994; Zailani and Rajagopal, 2005). For forecast information, the communication content is, for example, early information about product changes, expected future demand changes not yet visible in the official forecast data, and changed batch sizes. Participation concerns the extent and frequency of personnel involvement in the customer-supplier communication (Mohr and Spekman, 1994), For example, in terms of site visits, time is spent on getting to know the other organization's staff, involving the other party in strategic work, collaborative planning and workshop discussions.

Trust, communication content and participation in information-sharing should consequently be important issues for achieving collaborative customer-supplier relationships. Trust, communication content and participation in information-sharing could also be expected to impact the information quality. Previous research indicates that high levels of information quality are associated with high levels of collaborative customer-supplier relationships ( $\mathrm{Li}$ and $\mathrm{Lin}, 2006$ ). The customer-supplier relationship should affect the understanding of each other's needs and requirements and the possibility to come to agreements and joint definitions (e.g. Lohman et al., 2004), i.e. to attain information quality validity. It is logical to believe that a more developed collaborative relationship, characterized by frequent and open communication and trust, also enables the received information to be considered trustworthy (i.e. credible), containing all necessary information and easy to understand and use (i.e. complete and concise), received within the right time and regarded as reliable. The collaborative relationship between the information sender and receiver could consequently be expected to have a great impact on several information quality dimensions. The impact may, however, vary for different relationship types and dimensions. Several links between the relationship type and quality dimensions are indirect, making it difficult but essential to explain the importance of the relationship for the perceived forecast information quality. Thus, the following hypothesis is generated: 
Full reference: Jonsson, P. and Gustavsson, M. 2008. The impact of supply chain relationships and automatic data communication and registration on forecast information quality. International Journal of Physical Distribution and Logistics Management. 38(4): 280-295.

H1: There is a positive relationship between increased collaborative relationship and perceived forecast information quality.

\section{Automatic data communication and registration}

Automatic data communication and registration comprise a second cause of high information quality. Different information communication technologies should have different impact on timeliness. For example, mail, fax and e-mail always result in some time delays, while on-line or frequent batch communication using Internet/Web, EDI, etc. could be considered free from time delays (Lim and Prashant, 2001; Feng and Yuan, 2006). Lack of communication standards using the different technologies, such as unstructured e-mail or phone messages instead of standardized EDI messages, is another source of information quality deficiencies, with possible impact on the completeness and conciseness of information quality. Manual interpretation and registration instead of automatic registration of information, using e.g. EDI, web-EDI, web portal, etc., in the supplier's system can also result in information quality deficiencies, by causing both time delay and registration errors reducing the reliability (e.g. Lindau, 1995). Previous studies show how the use of EDI results in generally better delivery performance (Ahmad and Schroeder, 2001), higher productivity, better financial performance, more information exchange and a higher level of trust between customer and supplier (Rassameethes et al., 2000). EDI usage also improves information quality in terms of data reliability (Mackay and Rosier, 1996). The increased use of different Internet services such as web portals can also help in driving the supply chain members toward an integrated set of standards (Garcia-Dastugue and Lambert, 2003). Automatic data communication and registration of standardized information should consequently have positive impact on information quality. Defee and Stank (2005), for example, propose that high levels of standardization of data coding and order notation communication across supply chain entities are important for adopting supply chain strategies. In alignment with previous findings about advanced technology use (e.g. Boyer et al., 1997), it may be assumed that the possible information quality benefits of automatic data communication and registration cannot be achieved without first developing a collaborative relationship (Zineldin, 1998) between the sending and receiving parts. Both strong collaborative relationships and automatic data communication and registration are consequently considered necessary for the information receiver to perceive the information quality to be high. The following hypotheses can thus be generated:

H2: There is a positive relationship between automatic data communication and registration and high perceived forecast information quality.

H3: The interaction effect between collaborative relationship and automatic data communication and registration is positively correlated with high perceived forecast information quality.

\section{Control variables and conceptual model}

The perceptions of information quality may be affected by other issues than the customer-supplier relationship and automatic data communication and registration. Issues with positive impact on the information quality may be proactive information management, such as information process management and information life cycle management (Fisher et al., 2006). Information process management concerns information mapping to improve the information management process, regular reviews of what the information requirements are in the internal processes and at the suppliers, and confronting information producers with information quality deficiencies to get to the root of problems. Information life cycle management relates to maintaining the basic data quality by cleaning out old and redundant data from the information system and frequently updating existing data (APICS, 2007). 
Full reference: Jonsson, P. and Gustavsson, M. 2008. The impact of supply chain relationships and automatic data communication and registration on forecast information quality. International Journal of Physical Distribution and Logistics Management. 38(4): 280-295.

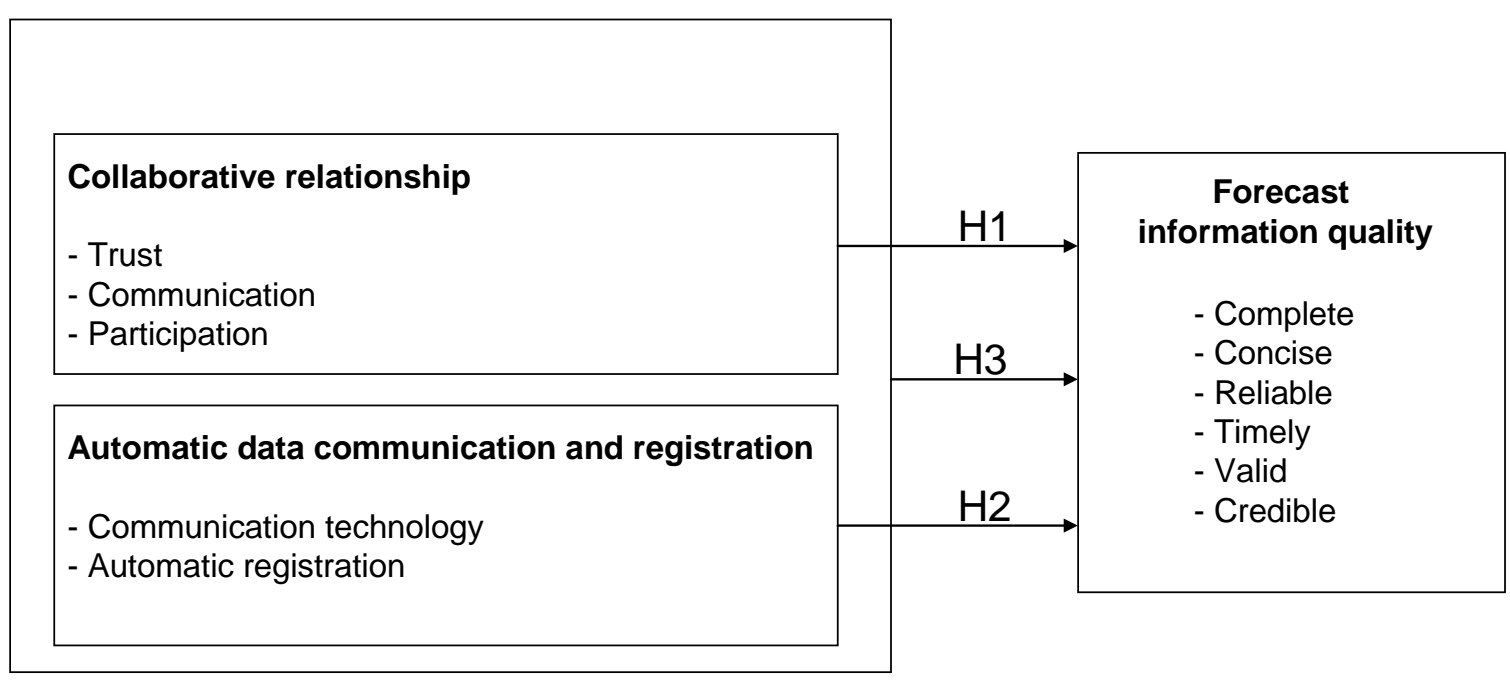

Figure 1. Conceptual model

\section{METHODOLOGY}

\section{Survey instrument}

Four groups of variables were included in the survey (Table 1). The six perceived information quality dimensions were defined in accordance with Gustavsson and Wänström (2008) and measured on seven-point single- and multiple-item scales. An information quality index, measured as the average of the six individual information quality indexes, was also developed. The collaborative relationships contained the variables of trust, communication and participation, measured with seven-point multipleitem scales derived from Zineldin (1998) and Zineldin and Jonsson (2000). The variable of communication measures the content of the communication, and the variable of participation measures the personnel involvement in the communication in accordance with Mohr and Spekman (1994) and Spekman et al. (1998). The three relationship variables were adjusted to relate to exchange of forecast information.

Automatic data communication and registration of forecast information were measured as two variables on nominal scales. The first asked the respondents about the communication technologies used, with the following five response alternatives: phone, fax, mail, e-mail and EDI. E-mail and EDI were coded as automatic communication. The second asked about the way of registering the data, with the following alternatives: manually, automatically, and by customer register in our system. Automatically and customer register in our system were coded as automatic registration. The variable "automatic data communication and registration" is coded as a binary variable, measuring whether both automatic communication and automatic registration of data are conducted at the same time. Those with both automatic data communication and automatic registration were coded as having "automatic data communication and registration”. The others were coded as not having automatic data communication and registration.

The two control variables, information process management and information life cycle management, were operationalised in accordance with Fisher et al. (2006) and measured with seven-point multipleitem scales. 
Full reference: Jonsson, P. and Gustavsson, M. 2008. The impact of supply chain relationships and automatic data communication and registration on forecast information quality. International Journal of Physical Distribution and Logistics Management. 38(4): 280-295.

Factor analysis with principal component analysis and varimax rotation and inter-item reliability test using Cronbach's alpha were used for the variables based on multiple-item scales. All variables loaded on single factors and showed reliable alpha values. The information quality index contained one variable (valid) with a factor loading of 0.5 . This variable was kept in the index because it should be an important dimension of the index and because of its high alpha value. Table I defines and summarizes means, standard deviations and alphas for the variables.

\section{Data collection}

The population of the study was manufacturing companies in all types of industries with an own production facility, with more than 50 employees. 900 E-mail addresses were selected from the Swedish address database (PAR), 60 of these did not have production and where thereby excluded. An e-mail with a link to a web survey was distributed to all these addresses in March, 2007. 219 full responses were received, which corresponds to a response rate of $26 \%$. Two e-mail reminders were sent out to the population and 276 non-response companies were contacted and asked for the reasons of not responding. The majority of the 276 (63\%) either asked for a new e-mail and promised to answer or gave us a new contact person at the company to whom the web survey was sent. Five companies (2\%) claimed that they did not have the knowledge to answer the questions, another five worked at companies without a production facility and 92 (33\%) did not have the time. Most non-responses are thus considered relevant for the population and should be included in the response rate calculation.

Table I. Defining informational relationship, information quality and control variables

A. Information Quality - All questions on 7-point Likert scales anchored by "I do not agree for this information type” and "I agree fully regarding this information type". For constructs with two measures, the mean of these measures is used.

\begin{tabular}{l|c|} 
A1. Complete: a) The information includes all necessary values. b) The information includes all & Factor loadings*1 \\
necessary explanations of the values. (Summated scale: Complete $=(\mathrm{A} 1 \mathrm{a}+\mathrm{A} 1 \mathrm{~b}) / 2)$ & 0.73 \\
A2. Concise: The information can be used directly, without reworking. & 0.67 \\
A3. Reliable: The forecast error is low and the forecast reflects true demand. & 0.76 \\
A4. Timely: The information is received in time for the planning task. & 0.73 \\
A5. Valid: The customer uses the same measures as your company. & 0.49 \\
A6. Credible: The information contains few errors, i.e. the forecast error is low and the forecast & 0.73 \\
reflects the real demand well. & \\
& \\
IQ index: (A1+A2+A3+A4+A5+A6)/6, Cronbach's alpha 0.78 &
\end{tabular}

B. Data communication and registration - (Automatic data communication and registration = (B1d OR B1e) AND (B2b OR B2c))

B1. Communication technology used (a. phone, b. fax, c. mail, d. e-mail, e. EDI)

B2. Automatic registration of data (a. manually typed in our ERP system, b. automatically up-loaded in our ERP system, c. Customer registers in our ERP system)

C. Collaborative relationship - All questions on 7-point Likert scales from "I do not agree" and "I fully agree".

C1. Trust, Mean (SD) 4.46 (1.30), Cronbach's alpha 0.86

a) Our interests are included in the customers' decision-making.

Factor loadings*

b) The customer is always honest and sincere in our communication.

0.71

c) Our staff trusts the customers' organization.

d) The success of our company is important to the customer.

0.87

0.87

e) The customer spends enough amounts of time and involvement on the relationship.

C2 Communication, Mean (SD) 4.58 (1.50), Cronbach's alpha 0.87

a) The customer keeps us informed on product changes.

0.81

0.80

b) The customer keeps us informed on future demand changes.

c) The customer keeps us informed on changes in batch sizes.

C3 Participation, Mean (SD) 4.15 (1.37), Cronbach's alpha 0.84

a) The customer visits us frequently.

Factor loadings*

0.84

0.91

0.91

Factor loadings*

0.84 
Full reference: Jonsson, P. and Gustavsson, M. 2008. The impact of supply chain relationships and automatic data communication and registration on forecast information quality. International Journal of Physical Distribution and Logistics Management. 38(4): 280-295.

b) We visit the customer frequently.

c) The customer spends a lot of time on getting to know our staff.

0.66

0.81

d) The customer frequently discusses new possibilities with us.

0.81

e) The customer involves us in strategic work and collaborative planning to improve overall

0.81 performance.

D. Control variables

D1 Information process management, Mean (SD) 4.12 (1.36), Cronbach’s alpha 0.82. 7-point Likert scales anchored by "We do not use this at all" and "This is a frequently used routine or practice for us".

a) We use information mapping to improve our information management.

b) We do regular reviews of what the information requirements are in the internal processes.

c) We do regular reviews of what the information requirements are at the suppliers.

d) We confront information producers with IQ deficiencies to get to the root of the problem.

D2 Information life cycle management, Mean (SD) 4.60 (1.43), Cronbach’s alpha 0.71. 7-point Likert scales anchored by "We do not use this at all" and "This is a frequently used routine or practice for us".

a) We clean out old data from our information systems.

b) We clean our information systems from duplicates.

c) We regularly update our ERP data.

*Principal component factor analysis (Varimax rotation), ${ }^{1} \mathrm{IQ}$ index

Factor loadings*

Company size and customer specifics of the respondents are described in Table II, showing that the respondents represent a wide spread of different company types.

Table II. Respondents' company and customer characteristics

\begin{tabular}{|l|c|}
\hline Variable & No. of respondents (\% of all 219) \\
\hline Fewer than 100 employees & $120(55 \%)$ \\
\hline Turnover larger than $€ 60 \mathrm{M}$ & $60(27 \%)$ \\
\hline Main customer stands for $>25 \%$ of turnover & $45(21 \%)$ \\
\hline Distance to main customer $>100 \mathrm{~km}$ & $86(39 \%)$ \\
\hline Respondent is an OEM, not a supplier & $50(23 \%)$ \\
\hline Items delivered to the main customer are customer-specific & $58(26 \%)$ \\
\hline
\end{tabular}

The non-response bias was analysed by comparing the industry affiliation and company sizes of the respondents and the entire selection (Table III). Chi-square tests could not reveal any difference between respondents and the full selection, regarding industry. There is a significant bias towards medium sized companies among the respondents. This bias is however not considered to impact the findings, because there is no clear bias towards large or small companies.

Table III. Industries and sizes of selection and respondents

\begin{tabular}{|l|c|c|c|c|}
\hline Industry & Selection (No.) & Selection (\%) & Responses (No.) & Responses (\%) \\
\hline Mechanical engineering and textile industries & 696 & $77 \%$ & 148 & $68 \%$ \\
\hline Process type industries (food, chemistry, paper) & 209 & $23 \%$ & 71 & $32 \%$ \\
\hline Size (turnover) & & & & \\
\hline$<€ 10 \mathrm{M}$ & 196 & $22 \%$ & 42 & $19 \%$ \\
\hline$€ 10-50 \mathrm{M}$ & 394 & $44 \%$ & 117 & $53 \%$ \\
\hline$>€ 50$ & 315 & $35 \%$ & 60 & $27 \%$ \\
\hline
\end{tabular}


Full reference: Jonsson, P. and Gustavsson, M. 2008. The impact of supply chain relationships and automatic data communication and registration on forecast information quality. International Journal of Physical Distribution and Logistics Management. 38(4): 280-295.

\section{FINDINGS}

The analysis contains three parts, one related to each of the hypotheses.

\section{Collaborative relationships and information quality}

Table IV shows correlations between the collaborative relationship variables and the information quality dimensions. Timeliness and credibility are significantly correlated with all three relationship variables. Reliability and completeness are significantly correlated with two of the relationship variables on the $\mathrm{p}<0.01$ levels. A collaborative relationship allows a dialogue about the importance of forecasts, and may also increase the general focus on the forecasting process, which may explain why reliability and timeliness are correlated with the relationship variables. The relationship with completeness could also be explained by the dialogue, because it allows the customer firm to understand the information needs of the supplier. Credibility measures to what extent the supplier trusts the received forecast. This dimension has an obvious correlation with the relationship variables. It is also highly correlated (and significant $\mathrm{p}<0.01$ ) with the reliability dimension. Two variables were significantly correlated with conciseness, but only on the $\mathrm{p}<0.05$ levels. The relationships are expected, since a collaborative relationship should make it more possible for the sender to prepare data that are easy for the receiver to use. However, the characteristics of the communication strategy should have a more direct effect on conciseness. Communication, but especially participation, allows synchronization of definitions and discussion about what forecast information to communicate and how to communicate it. It is somewhat surprising that the participation variable is significantly correlated with only two of the six information quality dimensions. However, participation is an important cause of trust (Zineldin and Jonsson, 2000), so there should at least be a strong indirect relationship between participation and forecast information quality. To trust the customer and the customer communicating planning-related information seem to be the relationship variables with most important information quality impact. Trust is often considered by far the most important variable for managing supply chain strategies and achieving supply chain performance (e.g. Spekman et al., 1998; Fynes et al., 2005; Narasimhan and Nair, 2005). This is consequently also the way to achieve high-quality information exchange in supply chains. No relationship variable was significantly correlated with forecast information validity. A reason for this could be that forecast information details may not be discussed in the customer-supplier communication. Another possible reason is that validity was the dimension with the highest mean among all information quality dimensions, and was therefore not considered as critical as the other quality dimension (e.g. Gustavsson and Jonsson, 2007). Hypothesis 1 was consequently verified for all information quality variables except for validity, especially for the trust and communication variables.

Table IV. Pearson correlations between collaborative relationship and information quality

\begin{tabular}{|l|l|l|l|l|l|l|}
\hline \multirow{2}{*}{$\begin{array}{l}\text { Collaborative } \\
\text { relationship }\end{array}$} & \multicolumn{5}{|c|}{ Forecast information quality by dimension } \\
\cline { 2 - 7 } & Complete & Concise & Reliable & Timely & Valid & Credible \\
\hline Trust & $0.22^{* *}$ & $0.19^{*}$ & $0.24^{* *}$ & $0.29^{* *}$ & -0.03 & $0.32^{* *}$ \\
\hline Communication & $0.22^{* *}$ & $0.18^{*}$ & $0.23^{* *}$ & $0.18^{*}$ & 0.02 & $0.23^{* *}$ \\
\hline Participation & 0.09 & 0.01 & 0.06 & $0.20^{*}$ & 0.06 & $0.28^{* *}$ \\
\hline
\end{tabular}

$*$ Two-tailed significances at the $\mathrm{p}<0.05$ level; ** Two-tailed significances at the $\mathrm{p}<0.01$ level

Data communication and registration and information quality

The five alternatives for forecast communication and the three for forecast data registration were used to identify two groups of respondents, those with and those without automatic data communication and registration, respectively. Those using e-mail or EDI in combination with automatic registration or customer registration in the supplier's system were coded as having "automatic data communication 
Full reference: Jonsson, P. and Gustavsson, M. 2008. The impact of supply chain relationships and automatic data communication and registration on forecast information quality. International Journal of Physical Distribution and Logistics Management. 38(4): 280-295.

and registration”. The others were coded as not having it. The group without automatic data communication and registration had 97 respondents compared to 42 for the automatic group (Table V), indicating that automatic data communication and registration as defined here are not very common in Swedish companies. 80 were coded as either having automatic data communication and registration or not having it. Consequently, several companies which were excluded from the analysis had implemented automatic data communication or automatic data registration but not both.

Table V. High and low automatic data communication and registration and information quality

\begin{tabular}{|l|c|c|l|}
\hline $\begin{array}{l}\text { Forecast information quality } \\
\text { dimension }\end{array}$ & $\begin{array}{l}\text { Not automatic data communication } \\
\text { and registration (n=97) }\end{array}$ & $\begin{array}{l}\text { Automatic data communication } \\
\text { and registration (n=42) }\end{array}$ & F-stats \\
\hline Complete, Mean (SD) & $4.79(1.96)$ & $6.02(1.13)$ & $3.80^{* *}$ \\
\hline Concise, Mean (SD) & $3.77(2.18)$ & $4.90(2.02)$ & $2.89^{* *}$ \\
\hline Reliable, Mean (SD) & $3.88(1.69)$ & $4.59(1.65)$ & $2.26^{*}$ \\
\hline Timely, Mean (SD) & $4.01(2.00)$ & $4.88(1.71)$ & $2.47^{*}$ \\
\hline Valid, Mean (SD) & $5.23(1.86)$ & $6.15(0.95)$ & $2.95^{* *}$ \\
\hline Credible, Mean (SD) & $4.35(1.56)$ & $4.88(1.68)$ & 1.80 \\
\hline
\end{tabular}

Note: T-tests, ${ }^{* *}$ Sign on $\mathrm{p}<0.01$ level, $*$ Sign on $\mathrm{p}<0.05$ level

Table $\mathrm{V}$ describes the statistics, comparing the two groups of data communication and registration, testing hypothesis 2. The information quality in the automatic group is significantly higher for all dimensions, except for credibility, compared to the non-automatic group. T-tests could not reveal any significant $(p<0.05)$ difference between the groups regarding the level of trust, communication and participation. The relationship type in the two groups should consequently not bias the findings. Reliability and timeliness, which were significantly correlated with the collaborative relationship, are also significantly related to automatic data communication and registration but only on the $\mathrm{p}<0.05$ level. The relationship between timeliness and automatic data communication and registration is obvious because time delays may occur without automation. A possible explanation to the relationship with reliability may be that those with automatic data communication and registration may send delivery schedules to a larger extent and may have more frequent information exchange than those without automatic data communication and registration. The dimensions with most significant differences $(\mathrm{p}<0.01)$ were completeness, conciseness and validity. They deal with the detailed data included in, and the format of, the received document. These issues should be direct results of automatic communication because they benefited from standardized modes of data transfer. Credibility was the only non-significant dimension. Hypothesis 2 was consequently verified for all dimensions except credibility.

\section{Combined effect on information quality}

Multiple regression analyses were used to test the combined effect of collaborative relationships and automatic data communication and registration on the six perceived information quality dimensions. Pearson correlation between the collaborative relationship variables (trust, communication, participation), automatic data communication and registration and control variables (information process management and information life cycle management) indicate some high correlation coefficients, over 0.4 (Table VI). Some multi-collinearity is consequently expected in the regression models. In order to minimize the multi-collinearity, only the collaborative relationship variable having the highest correlation with the information quality index was included in the regression models. Six regression models were developed, with the respective information quality dimension as dependent variable and trust, and automatic data communication and registration, information process 
Full reference: Jonsson, P. and Gustavsson, M. 2008. The impact of supply chain relationships and automatic data communication and registration on forecast information quality. International Journal of Physical Distribution and Logistics Management. 38(4): 280-295.

management and information life cycle management as independent variables. Table VII shows beta, $\mathrm{R}^{2}$ and F-statistics for the six regression models.

Table VI. Spearman correlations between variables

\begin{tabular}{|c|c|c|c|c|c|c|c|}
\hline & Trust & Communication & Participation & Automation & $\begin{array}{c}\text { Info process } \\
\text { management }\end{array}$ & $\begin{array}{c}\text { Info life } \\
\text { cycle } \\
\text { management }\end{array}$ & IQ index \\
\hline Trust & - & $0.62^{* *}$ & $0.52^{* *}$ & -0.03 & $0.25^{* *}$ & $0.22^{* *}$ & $0.26^{* *}$ \\
\hline Communication & & - & $0.49^{* *}$ & 0.02 & $0.19^{* *}$ & 0.09 & $0.25^{* *}$ \\
\hline Participation & & & - & 0.07 & $0.16^{*}$ & $0.16^{*}$ & 0.14 \\
\hline Automation & & & & - & $0.19^{*}$ & $0.13^{*}$ & $0.34^{* *}$ \\
\hline $\begin{array}{c}\text { Info process } \\
\text { management }\end{array}$ & & & & - & $0.44^{* *}$ & $0.20^{*}$ \\
\hline $\begin{array}{c}\text { Info life cycle } \\
\text { management }\end{array}$ & & & & & - & $0.31^{* *}$ \\
\hline IQ index & & & & & & & - \\
\hline
\end{tabular}

${ }^{*} \mathrm{p}<0.05,{ }^{* *} \mathrm{p}<0.01$

All regression models had significant $(\mathrm{p}<0.05) \mathrm{F}$ values, except for the one with concise information as dependent variable. The four models with complete, timely, valid and credible, respectively, as dependent variables had highest $\mathrm{R}^{2}$ figures, in the 0.125 to 0.215 range.

Information process management was not significant in any of the models. Information life cycle management, however, was significant in the models measuring complete, timely and valid information. Focusing on and actively working with the basic data files and maintaining them are, consequently, important for ensuring communication of complete, timely and valid information. Information life cycle management was the most significant independent variable in these three models. However, $\mathrm{R}^{2}$ increased significantly from 0.096 to 0.215 for complete, from 0.092 to 0.177 for timely, and from 0.069 to 0.128 for valid when including the trust and automatic data communication and registration variables.

Trust and automatic data communication and registration have positive impact on $\mathrm{R}^{2}$ in all six regression models. Trust but not automatic data communication and registration is significant in the model of credible information. Automatic data communication and registration but not trust is significant in the models of complete, concise and valid, while both trust and automatic data communication and registration are significant in the models of reliable and timely.

This third analysis consequently verifies that it is not enough only to have collaborative relationships or automatic data communication and registration; a combination of both variables is sometimes necessary for high perceived information quality. This was especially true for reliable and timely information. Hence, we conclude that hypothesis 3 is verified for several of the information quality dimensions. 
Full reference: Jonsson, P. and Gustavsson, M. 2008. The impact of supply chain relationships and automatic data communication and registration on forecast information quality. International Journal of Physical Distribution and Logistics Management. 38(4): 280-295.

Table VII. Regression of forecast information quality with trust and automation as independent variables

\begin{tabular}{|c|c|c|c|c|}
\hline Dependent variable & Independent variables & $\mathrm{b}$ & 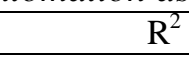 & 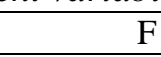 \\
\hline Complete & $\begin{array}{l}\text { Info process management } \\
\text { Info life cycle management } \\
\text { Trust } \\
\text { Automatic }\end{array}$ & $\begin{array}{l}-0.17 \\
0.38^{* *} \\
0.16 \\
0.28^{* *}\end{array}$ & 0.215 & $9.47 * *$ \\
\hline Concise & $\begin{array}{l}\text { Info process management } \\
\text { Info life cycle management } \\
\text { Trust } \\
\text { Automatic }\end{array}$ & $\begin{array}{l}-0.04 \\
0.07 \\
0.12 \\
0.22 *\end{array}$ & 0.037 & 2.17 \\
\hline Reliable & $\begin{array}{l}\text { Info process management } \\
\text { Info life cycle management } \\
\text { Trust } \\
\text { Automatic }\end{array}$ & $\begin{array}{l}-0.07 \\
0.09 \\
0.24^{*} \\
0.19 *\end{array}$ & 0.060 & $2.87 *$ \\
\hline Timely & $\begin{array}{l}\text { Info process management } \\
\text { Info life cycle management } \\
\text { Trust } \\
\text { Automatic }\end{array}$ & $\begin{array}{l}-0.14 \\
0.36^{* *} \\
0.23^{*} \\
0.18^{*}\end{array}$ & 0.177 & $7.42^{* *}$ \\
\hline Valid & $\begin{array}{l}\text { Info process management } \\
\text { Info life cycle management } \\
\text { Trust } \\
\text { Automatic }\end{array}$ & $\begin{array}{l}-0.20 \\
0.37 * * \\
0.07 \\
0.23 * *\end{array}$ & 0.128 & $5.17 * *$ \\
\hline Credible & $\begin{array}{l}\text { Info process management } \\
\text { Info life cycle management } \\
\text { Trust } \\
\text { Automatic }\end{array}$ & $\begin{array}{l}0.01 \\
0.14 \\
0.29 * * \\
0.14\end{array}$ & 0.125 & $5.35^{* *}$ \\
\hline
\end{tabular}

${ }^{*} \mathrm{p}<0.05,{ }^{* *} \mathrm{p}<0.01$

\section{DISCUSSION}

The study shows that the perceived forecast information quality, when receiving forecasts from a downstream customer in the supply chain, can be improved by developing a collaborative relationship - characterized by trust, communication of planning information, participation in personal meetings and involvement between people from the two organizations - and by automating the communication and registration of the forecast data. The generally perceived information quality is higher when collaborative relationships and automatic data communication and registration are developed at the same time, which is in line with previous research about advanced technology implementation and usage (e.g. Boyer et al., 1997).

The information quality dimensions of conciseness and completeness refer to the ease of using the received data in practice. Validity is related to the standardization and format of the communicated data. The perceived quality of these dimensions is affected to a great extent by the data communication and registration. Credibility, on the other hand, concerns trusting the received forecast, and is mainly affected by the relationship type. The timeliness and reliability are affected by the collaborative relationship type and by data communication and registration to about the same extent. Consequently, the status of some information quality dimensions is primarily a result of the type and degree of 
Full reference: Jonsson, P. and Gustavsson, M. 2008. The impact of supply chain relationships and automatic data communication and registration on forecast information quality. International Journal of Physical Distribution and Logistics Management. 38(4): 280-295.

collaborative relationship between sending and receiving parts. Other dimensions are mainly affected by how the data are communicated and registered, while some also depend appreciably on the type of relationship. In order to improve the forecast information quality, it is consequently first necessary to understand which information quality dimension is to be improved, because the causes of deficiencies are different for different dimensions.

It has thus emerged that automatic data communication and registration of forecast information between the customer's and supplier's planning systems and developing a collaborative relationship are both important for achieving high information quality. The existence of a collaborative relationship, not only exchange of high-quality information, is identified as important for managing most supply chain strategies (e.g. Spekman et al., 1998). There are also several other potentially positive effects of automatic data communication and registration (Ahmed and Schroeder, 2001), for example the importance of deciding and defining which data to communicate and how to communicate them in a standardized way. The majority of companies had developed collaborative relationships. However, this and other studies show that only a few companies have developed automatic data communication and registration (e.g. Straube, 2006), which should consequently impact the generally perceived forecast information quality and the possibility of developing successful supply chain strategies. Only a minority of the respondents were found to have automatic data communication and registration at the same time as a highly collaborative relationship.

\section{CONCLUSIONS}

The analysis concludes that a customer-supplier collaborative relationship and automatic data communication and registration have significant impact on the perceived information quality of forecasts received from a downstream customer in the supply chain. The reliability and timeliness of the forecast are affected to about the same extent by both the relationship type and the type of data communication and registration. Credibility depends primarily on the relationship type, while the conciseness and validity of the received forecast are operative attributes resulting mainly from the type of data communication and registration. Completeness is mainly affected by automatic data communication and registration, but relationship type is also significantly correlated with completeness. The conclusions explaining how various dimensions of forecast information quality are affected by different factors are thus a guide on how to differentiate information quality improvement work in different situations.

The existence of a collaborative relationship and of automatic data communication and registration impacts the perceived information quality for all quality dimensions in positive ways. Numerous companies have not implemented supply chain strategies characterized by both collaborative relationships and automatic data communication and registration. This implies a large potential for improvement in industry. Studies have shown generally positive effects of supply chain integration. There is, however, a lack of studies explaining the performance effect of high information quality exchange. Such studies will be necessary in order to understand how much effort to spend on improving the forecast information quality in supply chains.

\section{REFERENCES}

Ahmad, S. and Schroeder, R. G. (2001), "The impact of electronic data interchange on delivery performance", Production and Operations Management, Vol. 10, No. 1, pp. 16-30.

Anderson, J. and Narus, J. (1990), "A model of distributor-firm and manufacturer-firm working partnership", Journal of Marketing, Vol. 54, No. 1, pp. 42-58. 
Full reference: Jonsson, P. and Gustavsson, M. 2008. The impact of supply chain relationships and automatic data communication and registration on forecast information quality. International Journal of Physical Distribution and Logistics Management. 38(4): 280-295.

APICS (2007), "Using information technology to enable supply chain management", APICS certified supply chain professional learning system, Module 4, APICS, Alexandria.

Boyer, K., Leong, K, Ward, P, Krajewski, L. (1997), "Unlocking the potential of advanced manufacturing technologies”, Journal of Operations Management, Vol. 15, No. 4, pp. 331-347.

Cachon, G.P., Fisher, M. (2000). "Supply chain inventory management and the value of shared information”. Management Science, Vol. 46, No. 8, pp. 1032-1048.

Closs, D. J., Goldsby, T. J. and Clinton, S. R. (1997), "Information technology influences on world class logistics capability", International Journal of Physical Distribution \& Logistics Management, Vol. 27, No. 1, pp. 4-17.

Daugherty, P. J., Myers, M. B. and Autry, C. W. (1999), "Automatic replenishment programs: an empirical examination", Journal of Business Logistics, Vol. 20, No. 2, pp. 63-82.

Defee, C. and Stank, T. (2005), "Applying the strategy-structure-performance paradigm to the supply chain environment", International Journal of Logistics Management, Vol. 16, No. 1, pp. 28-50.

Feng, C.-M. and Yuan, C.-Y. (2006), "The Impact of Information and Communication Technologies on Logistics Management", International Journal of Management, Vol. 23, No. 4, pp. 909-944.

Fynes, B., Voss, C., de Burca, S. (2005), "The impact of supply chain dynamics on manufacturing performance", International Journal of Operations and Production Management, Vol. 25, No. 1, pp. 6-19.

Fisher, C., Lauria, E., Chengalur-Smith, S. and Wang, R. (2006), Introduction to Information Quality, M.I.T. Information Quality Program Publications, MIT, Boston.

Forslund, H. and Jonsson, P. (2007), "The impact of forecast information quality on supply chain performance", International Journal of Operations and Production Management, Vol. 27, No. 1, pp. 90-107.

Garcia-Dastugue, S. and Lambert, D. (2003), "Internet-enabled coordination in the supply chain", Industrial Marketing Management, Vol. 32, No. 3, pp. 251-263.

Gustavsson, M. and Jonsson, P. (2007), "Information quality deficiencies and consequences in supply chain information exchange", Proceedings of the annual NOFOMA conference 2007.

Gustavsson, M. and Wänström, C. (2008), "Assessing information quality in manufacturing planning and control processes", Internal publishing series, Division of logistics \& transportation, Chalmers University of Technology, Sweden.

Kwon, I-W. and Suh, T. (2005), "Trust, commitment and relationships in supply chain management: a path analysis", Supply Chain management: An international journal, Vol. 10, No. 1, pp. 26-33.

Kelle, P., Akbulut, A. (2005), "The role of ERP tools in supply chain information sharing, cooperation and cost optimizing”, International Journal of Production Economics, Vol. 93-94, pp. 41-52.

Lee, Y., Strong, D., Kahn, B., Wang, R. (2002), “AIMQ: a methodology for information quality assessment”, Information \& Management, Vol. 40, No. 2, pp. 133-146.

Li, S. and Lin, B. (2006), "Accessing information sharing and information quality in supply chain management", Decision Support Systems, Vol. 42, No. 3, pp. 1641-1656.

Lim, D. and Prashant, C. P. (2001), "EDI in strategic supply chain: impact on customer service", International Journal of Information Management, Vol. 21, pp. 193-211.

Lindau, R.A. (1995), The impact of high-quality information on performance in manufacturing. Doctoral thesis, Chalmers University of Technology, Göteborg.

Lohman, C., Fortuin, L. and Wouters, M. (2004), Designing a performance measurement system: a case study. European Journal of Operational Research, Vol. 156, pp. 267-286.

Mackay, D. and Rosier, M. (1996), "Measuring organizational benefits of EDI diffusion - A case of the Australian automotive industry", International Journal of Physical Distribution \& Logistics Management, Vol. 26, No. 10, pp. 60-78.

Mayer, R., Davis, J., Schoorman, F. (1995), "An integrative model of organizational trust", Academy of Management Review, Vol. 29, No. 3, pp. 709-734.

McCarthy, T., Golicic, S. (2002), "Implementing collaborative forecasting to improve supply chain performance", International Journal of Physical Distribution \& Logistics Management, Vol. 32, No. 6, pp. 431-454. 
Full reference: Jonsson, P. and Gustavsson, M. 2008. The impact of supply chain relationships and automatic data communication and registration on forecast information quality. International Journal of Physical Distribution and Logistics Management. 38(4): 280-295.

Min, S. and Mentzer, J. (2000), "The role of marketing in supply chain management", International Journal of Physical Distribution and Logistics Management, Vol. 30, No. 9, pp. 765-787.

Mohr, J. and Spekman, R. 81994), "Characteristics of partnership success: partnership attitudes, communication behaviour, and conflict resolution techniques", Strategic Management Journal, Vol. 15, No. 2, pp. 135-152.

Moorman, C., Deshpande, R., Zaltman, G. (1993), "Factor affecting trust in market research relationships", Journal of Marketing, Vol. 57, No. 1, pp. 81-101.

Narasimhan, R. and Nair, A. (2005), "The antecedent role of quality, information sharing and supply chain proximity on strategic alliance formation and performance", International Journal of Production Economics, Vol. 96, pp. 301-313.

Petersen, K., Ragatz, G., Monczka, R. (2005), "An examination of collaborative planning effectiveness and supply chain performance", The Journal of Supply Chain Management, Vol. 41, No. 2, pp. 14-25.

Rassameethes, B., Susumu, K. and LeBlanc, L. J. (2000), "EDI performance in the automotive supply chain", International Journal of Technology Management, Vol. 20, No. 3/4, pp. 287-303.

Spekman, R., Kamauff, J., Myhr, N. (1998), "An empirical investigation into supply chain management: a perspective on partnership", Supply Chain Management: An international journal, Vol. 3, No. 2, pp. 53-67.

Straube (ed.) (2006), Trends and strategies in logistics - agenda for logistics management in 2010, German Logistics Ass.

van der Vorst, J. and Beulens, A. (2002), "Identifying sources of uncertainty to generate supply chain redesign strategies", International Journal of Physical Distribution \& Logistics Management, Vol. 32, No. 6, pp. 409-430.

Zailani, S. and Rajagopal, P. (2005), "Supply chain integration and performance: US versus East Asian companies", Supply Chain Management: An international journal, Vol. 10, No. 5, pp. 379-393.

Zineldin, M. (1998), “Towards an ecological collaborative relationship management”, European Journal of Marketing, Vol. 32, No. 11/12, pp. 1138-1164.

Zineldin, M. and Jonsson, P. (2000), "An examination of the main factors affecting trust/commitment in supplier-dealer relationships: an empirical study of Swedish wood industry”, The TQM Magazine, Vol. 12, No. 4, pp. 245-265. 